\title{
MAGNITUDE DRIFT EFFECT WINNER AND LOSER STOCKS: LQ45 AND FTSE100
}

\author{
Felita Tanuprasodjo \\ PT Hanjaya Mandala Sampoerna \\ Putu Anom Mahadwartha \\ Faculty of Business and Economics, Universitas Surabaya \\ anom@staff.ubaya.ac.id
}

\begin{abstract}
This research is aimed to examine and find out empirical evidence of magnitude drift effect on 10 winner LQ45, 10 loser LQ45, 5 winner FTSE100 Malaysia and 5 loser FTSE100 Malaysia. One sample t-test and independent sample t-test are used to test the magnitude drift effect. The result show the positive magnitude drift effect on Monday-Wednesday at 10 Winner LQ45 and 5 winner FTSE100, Monday-Tuesday at 10 Loser LQ45, Monday-Thursday at 5 Loser FTSE100 and the negative magnitude drift effect occurs on Thursday-Friday at 10 Winner LQ45 and 5 Loser FTSE100, Wednesday-Friday at 10 Loser LQ45 and Friday-Monday at 5 Winner FTSE100. Magnitude drift in Malaysia occurs more than magnitude drift in Indonesia.
\end{abstract}

Keywords: Market Anomaly, Days of the Week Effect, Magnitude Drift Effect

\begin{abstract}
Abstrak
Penelitian ini bertujuan untuk menguji dan menemukan adanya magnitude drift effect pada 10 winner LQ45, 10 loser LQ45, 5 winner FTSE100 Malaysia dan 5 loser FTSE100 Malaysia. Metode one sample t-test dan independent sample t-test digunakan untuk menguji adanya magnitude drift effect. Hasil dalam penelitian ini terdapat magnitude drift effect yang signifikan positif hari Senin-Rabu pada 10 Winner LQ 45 dan 5 Winner FTSE100, SeninSelasa pada 10 Loser LQ45, Senin-Kamis pada 5 Loser FTSE100. Magnitude drift yang signifikan negatif terjadi pada hari Kamis-Jumat pada 10 Winner LQ45 dan 5 Loser FTSE100, Rabu-Jumat pada 10 Loser LQ45 dan Jumat-Senin pada 5 Winner FTSE100. Magnitude drift lebih sering terjadi di Indonesia dibandingkan Malaysia.
\end{abstract}

Kata Kunci: Market Anomaly, Days of the Week Effect, Magnitude Drift Effect

JEL: G11, G14

\section{Research Background}

In 1970, Fama developed a theory of efficient market hypothesis (EMH), which states that the price will reflect all the information available in the market; making it difficult for investors to earn abnormal returns. Several studies have found that investors have a tendency to make mistakes in processing information due to their irrational behavior; thus allows market anomaly to take place. Market anomaly is a situation that is incompatible with the efficient market (Jones 1998). Various researchers continue to test EMH theory and some researchers found the phenomenon of market anomalies that are contrary to EMH theory. There are three important aspects to study related to anomaly research. First, the pattern of anomalies will have an impact on investors' trading strategies (Berk 2009). Second, anomalies can prove the validity of EMH (Lari et al. 2013). Third, many studies had addressed anomaly, but no clear explanation about 
the cause of the anomaly. These three things have made the researcher want to examine further the topic of market anomaly further.

Days of the week effect is the phenomenon of the difference of return from one day to another day (Damodaran 1996). Various researchers were trying to study in different countries. Cross 1973; French 1980; Keim and Stambaugh 1984; Aggarwal and Rivolli 1989 have consistently found the phenomenon of days of the week effect. Average return on Mondays tends to be lower than other days and the average return on Fridays tends to be higher than other days. This phenomenon is known as Monday effect and weekend effect.

In 1998, Fortune popularized and developed the term 'drift effect'. Fortune found that weekend drift effect is the tendency of stock prices to decline during weekends and back increasing during trading weekdays. Drift effect began to be the spotlight of current literature. Drift effect will provide information on whether the changes on stock price between days have significant differences that can initiate buy or sell decision. This study will prove that magnitude drift effect as the average of the difference on abnormal return between days that is significantly different with the average of the difference on abnormal return from other day.

The purpose of this study is to determine the magnitude drift effect on 10 winner stocks of LQ 45 and 10 loser stocks on LQ45, and 5 winner stocks on FTSE100 Malaysia and 5 loser stocks on FTSE100 Malaysia. This research is beneficial as it can be used as reference material regarding the study of magnitude drift effects. For investors, this research expected to be used as consideration in investing in the stock market so that the knowledge goes beyond what day do they should make buy or sell decision, but also to make sure that the day has a big difference of the average abnormal return thus resulting buy or sell decision by using the magnitude drift effect. For further research, this research is expected to be a useful reference.

\subsection{Hypothesis Development}

Efficient Market Hypothesis developed by Fama in 1970 defines an efficient market as a market that can fully reflect all available information (Megginson 2007). Fama (1970) classify the efficient market hypothesis is based on three kinds of information as follows, namely: weak, semi-strong and strong form.

Market efficiency on weak form is a hypothesis that the current share price is reflecting the information from the past, such as historical data on stock prices and trading volume. Market efficiency on semi-strong form is a hypothesis that the current share price is reflecting all the information published, such as from newspapers and financial reports. Market efficiency on a strong form is a hypothesis that the current share price is reflecting all the published information and private information.

Market anomaly is a phenomenon that against the efficient market hypothesis. Calendar anomaly is the part of market anomaly; which is a part of a market phenomenon. Jones (1998) states that if some events can be used to obtain abnormal return, then there is a possibility that investors will earn abnormal returns by relying on certain event. Calendar anomaly is related with changes in the stock price on certain day/month/year that could lead to days of the week effect.

Days of the week effect is an anomaly that shows the differences in the trading day affect the pattern of stock returns in a week (Alteza 2007). Thus, days of the week effect is a form of deviation from the concept of efficient market, in which the average of daily return of a stock is similar and does not differ significantly at the other trading days. The anomaly days of the week effect is found almost in all capital markets in the world. This research's hypothesis is to find significant differences in the average of daily abnormal return to zero.

\section{$\mathrm{H}_{1}$ : There are differences in the average of daily abnormal return}

Magnitude drift effect is the focus of this study. Various studies have attempted to prove the phenomenon of days of the week effect by finding significant differences in the 
average abnormal return between days, while the hypothesis development of this study is to examine the magnitude drift effect by looking for significant differences in the gap of average abnormal return on two different days. A significant difference reflects the significant change of abnormal return between days and this is used by investors to make buy or sell decision. A negative magnitude drift effect indicates that the difference of abnormal return during $t_{2}$ is greater than $t_{1}$ thus investor can buy during $t_{1}$ and sell during $t_{2}$, whereas a positive magnitude drift effect indicates that the difference of abnormal return during $t_{1}$ is greater than $t_{2}$ thus short sell can be done by sell during $\mathrm{t}_{1}$ and buy during $\mathrm{t}_{2}$.

\section{H2: There is a difference in the average of abnormal return between two different} days

\section{Research Method}

This research is basic research using conclusive descriptive comparative method. This research will provide an overview of drift effects in a systematic and quantitative way and comparing 10 winner stock LQ45 with 10 loser stock LQ45 and 5 winner stock FTSE100 Malaysia with 5 loser stock FTSE100 Malaysia so that the findings can be used as a basis for decision making.

The data used in this research is secondary data, namely in the form of time series data of daily stock price. Historical data are obtained from www.finance.yahoo.com. Target population and sample used in this research is 10 winner stock LQ45 and 10 loser stock LQ45, as well as 5 winner stock FTSE100 Malaysia and 5 loser stock FTSE100 Malaysia. The 10 winners stock LQ45 and 10 loser stock LQ45 in Indonesia is determined based on the 10 biggest cumulative returns and 10 smallest cumulative return of a group of stocks listed in LQ45. While for FTSE100 Malaysia, 5 winners stock and 5 losers stock is determined based on www.bursamalaysia.com. There are limitations in the data of FTSE100 Malaysia that has caused the researcher unable to use 10 winner stock and 10 loser stock, but instead only 5 winner stock and 5 losers stock. Data is collected in accordance with the needs of research. The steps taken are as follows:

i) Downloading statistical publications of LQ45 and FTSE100 based on www.idx.co.id and www.bursamalaysia.com.

ii) Determine the 10 winners stock and 10 loser stocks of stocks listed in LQ45 by calculating the biggest cumulative return and the smallest; while the determination of the 5 winners stock and 5 loser stock FTSE100 is based on data available in www.bursamalaysia.com.

iii) Download daily stock price of all stocks that are already included in 10 winners stock and 10 losers stock of LQ45 as well as 5 winner stock and 5 loser stock of FTSE100 during January $1^{\text {st }}, 2015$ - July $6^{\text {th }}, 2015$.

iv) Calculating the actual return of each stock selected as the 10 winners stock and 10 losers stock of LQ45 in Indonesia as well as 5 winners stock and 5 losers stock of FTSE100 Malaysia in January $1^{\text {st }}, 2015-$ July $6^{\text {th }}, 2015$ using the formula:

Actual Return $=($ current stock price - stock price in the previous period $) /$ stock price in the previous period

v) Calculate the beta and alpha of each stock from the regression results in the period January $1^{\text {st }}, 2015$ - June $7^{\text {th }}, 2015$.

vi) Download Indonesia's composite index and Malaysia's composite index for the observation period which is June $8^{\text {th }}$ to July $6^{\text {th }}, 2015$.

vii) Count $R_{m}$ for each composite index in Indonesia and Malaysia for the observation period June $8^{\text {th }}$ to July $6^{\text {th }}, 2015$ by using the formula:

$\mathrm{R}_{\mathrm{m}}=$ (today's composite index price - yesterday's composite index price) / yesterday's composite index price 
viii) Calculate the expected return on the observation period June $8^{\text {th }}$ to July $6^{\text {th }}, 2015$ by using the formula:

$\alpha$ is obtained from the result of step $\mathrm{v}$

$$
\text { Expected Return }=\alpha \mathrm{i}+\beta \mathrm{i} \cdot \mathrm{R}_{\mathrm{m}}
$$

$\beta$ is obtained from the result of step $\mathrm{v}$

$\mathrm{R}_{\mathrm{m}}$ is obtained from the result of step vii

ix) Calculate the abnormal return of the observation period of June $8^{\text {th }}$ to July $6^{\text {th }}, 2015$ by using the formula:

$$
\text { Abnormal Return = Actual Return }- \text { Expected Return }
$$

The actual return used during the observation period of June $8^{\text {th }}$ to July $6^{\text {th }}, 2015$ is calculated in step iv

The expected return used during the observation period of June $8^{\text {th }}$ to July $6^{\text {th }}, 2015$ is calculated in step vii

$\mathrm{x}$ ) The data of abnormal return is inputted into SPSS for being processed further

The method used in this research is descriptive analysis, Kolmogorov-Smirnov normality test, Run Test, Test of One Sample T-Test, and Test of Independent Sample T-Test. Descriptive statistics used in this research are mean, standard deviation, min, and max to describe research variables. Normality test was done by Kolmogorov-Smirnov test with the significance above $5 \%$. Run test was done by the run test methods in SPSS with the assumption of data randomness at $5 \%$ significance level.

The hypotheses test used in this research is one sample t-test and independent sample ttest. One sample t-test is a parametric test that aims to test whether the average value of a sample is significantly differs from a certain specified value. In this test the average abnormal return between days will be significantly compared with the value of 0 . If the null hypothesis is accepted then there is no significant difference in the average abnormal return to zero which means so there is no abnormal return. Conversely, if the null hypothesis is rejected then there is a significant difference in the average abnormal return to zero which means there is abnormal return. Significance used in this research is $10 \%$.

The test of independent sample t-test is used to determine whether there is a significant difference on average between the two populations by takes a look at the average of two samples. This test will compare two different samples or unrelated. If the null hypothesis is accepted then there is no significant difference in the average abnormal return of a sample and another sample. Conversely, if the null hypothesis is rejected then there is a significant difference in the average abnormal return of a sample to another sample. The significance used is $10 \%$.

\section{Result and Discussion}

\subsection{Days of the Week Effect LQ45}

Table 1. Descriptive Statistic Results for Days of the Week Effect in 10 Winners LQ45.

\begin{tabular}{cccccc} 
Day & $\mathrm{N}$ & Mean & Std. Deviation & Minimum & Maximum \\
\hline Monday & 50 & 0.0082 & 0.0226 & -0.0855 & 0.0436 \\
Tuesday & 40 & 0.0050 & 0.0261 & -0.0746 & 0.0704 \\
Wednesday & 40 & -0.0001 & 0.0273 & -0.0749 & 0.0513 \\
Thursday & 40 & -0.0046 & 0.0282 & -0.0768 & 0.0640 \\
Friday & 40 & 0.0057 & 0.0188 & -0.0257 & 0.0501 \\
\hline Total & 210 & 0.0031 & 0.0249 & -0.0855 & 0.0704 \\
\hline
\end{tabular}


Descriptive statistic result for days of the week effect on the 10 winner LQ45 shows that the highest average abnormal return is on Monday at 0.0082 with the minimum value of -0.0855 and maximum value of 0.0436; while the lowest average abnormal return is on Thursday with a value that is equal to -0.0046 with the range of -0.0768 as the minimum value to 0.0640 as the maximum value.

Table 2. Descriptive Statistic Results for Days of the Week Effect in 10 Losers LQ45.

\begin{tabular}{cccccc} 
Day & $\mathrm{N}$ & Mean & Std. Deviation & Minimum & Maximum \\
\hline Monday & 50 & 0.0015 & 0.0175 & -0.0493 & 0.0407 \\
Tuesday & 40 & -0.0038 & 0.0148 & -0.0289 & 0.0253 \\
Wednesday & 40 & -0.0072 & 0.0273 & -0.1222 & 0.0319 \\
Thursday & 40 & -0.0024 & 0.0296 & -0.1184 & 0.0515 \\
Friday & 40 & 0.0025 & 0.0166 & -0.0355 & 0.0548 \\
\hline Total & 210 & -0.0017 & 0.0219 & -0.1222 & 0.0548 \\
\hline
\end{tabular}

Descriptive statistic result for days of the week effect on the 10 loser LQ45 shows that the highest average abnormal return is on Friday at 0.0025 with the range of minimum value 0.0355 to maximum value of 0.0548 ; while the lowest average abnormal return is on Wednesday with a value that is equal to -0.0072 with the range of -0.1222 as the minimum value to 0.0319 as the maximum value.

Table 3. Summary of Daily Abnormal Return Test Result with Kolmogorov-Smirnov Normality Test, Run Test, and One Sample T-Test on 10 Winner LQ45 and 10 Loser LQ45.

\begin{tabular}{ccccccc}
\hline & \multicolumn{3}{c}{ 10 Winner LQ45 } & \multicolumn{3}{c}{ 10 Loser LQ45 } \\
\cline { 2 - 7 } Test & K-S & $\begin{array}{c}\text { Run } \\
\text { Test }\end{array}$ & $\begin{array}{c}\text { One } \\
\text { Sample } \\
\text { T-test }\end{array}$ & K-S & $\begin{array}{c}\text { Run } \\
\text { Test }\end{array}$ & $\begin{array}{c}\text { One } \\
\text { Sample } \\
\text { T-test }\end{array}$ \\
\hline Monday & 0.929 & 0.164 & $0.014^{* *}$ & 0.873 & 0.178 & 0.554 \\
Tuesday & 0.444 & 0.231 & 0.234 & 0.856 & 0.674 & 0.117 \\
Wednesday & 0.777 & 0.431 & 0.978 & 0.156 & 0.674 & 0.102 \\
Thursday & 0.945 & 0.619 & 0.308 & 0.537 & 0.755 & 0.604 \\
Friday & 0.893 & 0.631 & $0.061^{*}$ & 0.596 & 0.873 & 0.347 \\
\hline
\end{tabular}

Notes: symbol * illustrates the significance level below $10 \%$, symbol ** illustrates the significance level below $5 \%$.

Normality test is done by Kolmogorov-Smirnov at the significance level of 5\% indicates that the test is conducted on Monday, Tuesday, Wednesday, Thursday, and Friday for 10 winners of LQ45 and 10 losers of LQ45 are above 0.05, means the data is normal and further testing can be done. Run Test conducted with significance level at 5\% and the results are above 0.05 on Monday, Tuesday, Wednesday, Thursday, and Friday for 10 winner LQ45 and 10 loser LQ45; means the data has been distributed randomly and further testing can be done.

One sample t-test is used for hypotheses test differ from zero. The result shows that it is significant on Monday with the significance below 5\% and Friday with significantly below $10 \%$ for 10 winner LQ45, but there are no significant results for 10 loser LQ45. So, there is a significant abnormal return that is differ from zero on Monday and Friday for 10 winner LQ45 that indicates days of the week effect occurs on Monday and Friday, and there is no abnormal return that is significantly differ from zero for 10 loser LQ45 that indicates there is no days of 
the week effect for 10 loser LQ45.

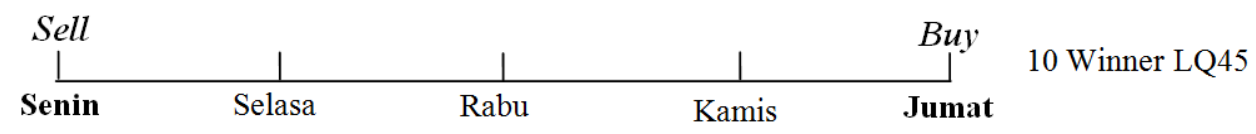

Figure 1. Summary Buy/Sell Decision on 10 Winner LQ45

Test for days of the week effect on 10 winner LQ45 indicates a significant difference of abnormal return on Monday and Friday with the average on Monday of 0.008 and average on Friday of 0.005 . Thus investors may decide to sell on Monday and buy on Friday for 10 winners LQ45. Various studies have consistently found that the average abnormal return on Monday is significantly the lowest and the average abnormal return on Friday is significantly the highest. This may be because of the self-fulfilling prophecy that caused investors to realize the prophecy itself; so that investors believe the results of previous studies by make a buy decision on Monday and sell decision on Friday. The high amount of stocks bought on Monday led to a high demand, thus stock price increased and this research finds that the average abnormal return on Monday is significantly positive compared to other days. By contrast, the high amount of stocks sold on Friday caused stock price to fall so that the average abnormal return on Friday is significantly differ from zero with the average abnormal return lower than Monday.

Based on the test results of independent sample t-test result, Monday and Friday are significantly different from Thursday. This is because the average abnormal return on Thursday is likely to be the most negative compared to other days but not significant. The standard deviation of Thursday is the greatest among all. Thus, investors should buy on Friday as it is significantly differ from zero and have an average abnormal return lower than Monday.

This is different from days of the week effect test on 10 losers LQ45, whereas there are no significant differences between days. It is suspected because of the difference between the average spread of share price during the highest and the lowest, as well as differences in the number of shares and price per share on the winner and loser LQ 45. The average spread on the winner's share price is greater than loser LQ45. This causes the average spread of share price on loser LQ45 smaller than winner LQ45, thus the possibility to earn abnormal return is smaller due to the price fluctuations that are not so enormous for loser LQ45 compared to winner LQ45. The sheer opportunities to earn abnormal return causes the absence of days of the week effect phenomenon on 10 loser LQ45. This is also supported by smaller market capitalization of loser compared to winner, thus the opportunity to gain abnormal returns on loser is more limited than winner.

\subsection{Magnitude Drift Effect LQ45}

Table 4. Descriptive Statistics Result for Magnitude Drift Effect in 10 Winners LQ45

\begin{tabular}{cccccc} 
Shift Day $(\Delta \mathrm{AR})$ & $\mathrm{N}$ & Mean & Std. Deviation & Minimum & Maximum \\
\hline Monday-Tuesday & 40 & 0.0065 & 0.0285 & -0.0466 & 0.0882 \\
Monday-Wednesday & 40 & 0.0143 & 0.0335 & -0.0486 & 0.0965 \\
Monday-Thursday & 40 & 0.0098 & 0.0331 & -0.0903 & 0.0768 \\
Monday-Friday & 40 & 0.0044 & 0.0234 & -0.0368 & 0.0536 \\
Tuesday-Wednesday & 40 & 0.0067 & 0.0434 & -0.1008 & 0.1198 \\
Tuesday-Thursday & 40 & 0.0110 & 0.0361 & -0.0940 & 0.0865 \\
Tuesday-Friday & 40 & -0.0053 & 0.0369 & -0.0978 & 0.0591 \\
Wednesday-Thursday & 40 & 0.0081 & 0.0387 & -0.0533 & 0.1123
\end{tabular}




\begin{tabular}{cccccc} 
Wednesday-Friday & 40 & -0.0111 & 0.0346 & -0.0756 & 0.0706 \\
Thursday-Friday & 40 & -0.0171 & 0.0327 & -0.1189 & 0.0279 \\
\hline Total & 400 & 0.0024 & 0.0348 & -0.1189 & 0.1198 \\
\hline
\end{tabular}

Descriptive statistics result for magnitude of the drift effect in 10 winner LQ45 shows that the biggest positive average change on abnormal return occurs on Monday-Wednesday with the value of 0.0143 with the range of -0.0486 as minimum value, and 0.0965 as maximum value; and the biggest negative average change on abnormal return occurs on Thursday-Friday with the value of -0.0171 , and the range of -0.1189 as the minimum value to 0.0279 as the maximum value. The average of abnormal return change tends to be positive on Monday-Tuesday, Monday-Wednesday, Monday-Thursday, Monday-Friday, Tuesday-Wednesday, TuesdayThursday and Wednesday-Thursday; while the average of abnormal return changes tends to be negative on Tuesday-Friday, Wednesday-Friday, and Thursday-Friday. The biggest standard deviation occurs on Tuesday-Wednesday with average changes in abnormal returns of 0.0434 , minimum value of -0.1008 , and maximum value of 0.1198 means Tuesday-Wednesday has the biggest volatility on abnormal return change compared to other days.

Table 5. Descriptive Statistics Result of Magnitude Drift Effect on 10 Losers LQ45

\begin{tabular}{cccccc} 
Shift Day $(\Delta \mathrm{AR})$ & $\mathrm{N}$ & Mean & Std. Deviation & Minimum & Maximum \\
\hline Monday-Tuesday & 40 & 0.0064 & 0.0238 & -0.0410 & 0.0620 \\
Monday-Wednesday & 40 & 0.0099 & 0.0390 & -0.0812 & 0.1554 \\
Monday-Thursday & 40 & 0.0051 & 0.0380 & -0.0575 & 0.1462 \\
Monday-Friday & 40 & 0.0001 & 0.0239 & -0.0587 & 0.0458 \\
Tuesday-Wednesday & 40 & 0.0035 & 0.0296 & -0.0581 & 0.1185 \\
Tuesday-Thursday & 40 & -0.0013 & 0.0311 & -0.0634 & 0.1256 \\
Tuesday-Friday & 40 & -0.0063 & 0.0207 & -0.0584 & 0.0391 \\
Wednesday-Thursday & 40 & -0.0048 & 0.0404 & -0.1479 & 0.0897 \\
Wednesday-Friday & 40 & -0.0097 & 0.0346 & -0.1769 & 0.0345 \\
Thursday-Friday & 40 & -0.0049 & 0.0322 & -0.1172 & 0.0598 \\
\hline Total & 400 & 0.0000 & 0.0312 & -0.1769 & 0.1554 \\
\hline
\end{tabular}

Descriptive statistics result for magnitude of the drift effect in 10 loser LQ45 shows that the biggest positive average change on abnormal return occurs on Monday-Wednesday with the value of 0.0099 with the range of -0.0812 as minimum value, and 0.1554 as maximum value; and the biggest negative average change on abnormal return occurs on Wednesday-Friday with the value of -0.0097 , with the range of -0.1769 as the minimum value to 0.0345 as the maximum value. The average of abnormal return change tends to be positive on MondayTuesday, Monday-Wednesday, Monday-Thursday, Monday-Friday, and Tuesday-Wednesday; while the average of abnormal return changes tends to be negative on Tuesday-Thursday, Tuesday-Friday, Wednesday-Thursday, Wednesday-Friday, and Thursday-Friday. The biggest standard deviation occurs on Wednesday-Thursday with average changes in abnormal returns of 0.0404 , minimum value of -0.1479 , and maximum value of 0.0897 means WednesdayThursday has the biggest volatility on abnormal return change compared to other days. 
Table 6. Summary of Test Result with Magnitude Drift on Abnormal Return Daily using the Kolmogorov Smirnov Normality Test, Run Test, and One Sample T-Test on 10 Winner LQ45 and 10 Loser LQ45

\begin{tabular}{ccccccc}
\hline & \multicolumn{3}{c}{ 10 Winner LQ45 } & \multicolumn{3}{c}{ 10 Loser LQ45 } \\
\cline { 2 - 7 } Test & K-S & $\begin{array}{c}\text { Run } \\
\text { Test }\end{array}$ & $\begin{array}{c}\text { One Sample } \\
\text { T-test }\end{array}$ & K-S & $\begin{array}{c}\text { Run } \\
\text { Test }\end{array}$ & $\begin{array}{c}\text { One Sample T- } \\
\text { test }\end{array}$ \\
\hline Monday-Tuesday & 0.929 & 0.432 & 0.160 & 0.368 & 1.000 & $0.099^{*}$ \\
Monday-Wednesday & 0.894 & 0.731 & $0.010^{* *}$ & 0.521 & 0.098 & 0.118 \\
Monday-Thursday & 0.961 & 0.873 & $0.067^{*}$ & 0.431 & 0.570 & 0.404 \\
Monday-Friday & 0.728 & 0.423 & 0.237 & 0.802 & 0.821 & 0.973 \\
Tuesday-Wednesday & 0.826 & 0.423 & 0.334 & 0.327 & 0.262 & 0.462 \\
Tuesday-Thursday & 0.945 & 0.035 & $0.061^{*}$ & 0.347 & 0.755 & 0.792 \\
Tuesday-Friday & 0.494 & 0.077 & 0.369 & 0.832 & 1.000 & $0.064^{*}$ \\
Wednesday-Thursday & 0.355 & 1.000 & 0.192 & 0.229 & 0.008 & 0.458 \\
Wednesday-Friday & 0.997 & 0.631 & $0.048^{* *}$ & 0.312 & 0.549 & $0.083^{*}$ \\
Thursday-Friday & 0.494 & 0.755 & $0.002^{* * *}$ & 0.821 & 0.987 & 0.338 \\
\hline
\end{tabular}

Notes: symbol * illustrates the significance level below $10 \%$, symbol ** illustrates the significance level below $5 \%$, symbol $* * *$ illustrates the significance level below $1 \%$.

Normality test is done by Kolmogorov-Smirnov at the significance level of 5\% indicates that magnitude drift effect test conducted on Monday-Tuesday, Monday-Wednesday, MondayThursday, Monday-Friday, Tuesday-Wednesday, Tuesday-Thursday, Tuesday-Friday, Wednesday-Thursday, Wednesday-Friday, and Thursday-Friday for 10 winners of LQ45 and 10 losers of LQ45 are above 0.05, means the data is normal and further testing can be done. Run Test conducted with significance level at 5\% and the results are above 0.05 on MondayTuesday, Monday-Wednesday, Monday-Thursday, Monday-Friday, Tuesday-Wednesday, Tuesday-Friday, Wednesday-Thursday, Wednesday-Friday, and Thursday-Friday for 10 winner LQ45 and on Monday-Tuesday, Monday-Wednesday, Monday-Thursday, Monday-Friday, Tuesday-Wednesday, Tuesday-Thursday, Tuesday-Friday, Wednesday-Friday, and ThursdayFriday for 10 loser LQ45; means the data has been distributed randomly. Run Test for TuesdayThursday on 10 winners LQ45 and Wednesday-Thursday on 10 losers LQ45 shows that it is under 0.05 , means the data is not distributed randomly.

One sample t-test is used for hypotheses test differ from zero. The result shows that it is significant on Thursday-Friday with the significance level below 1\%, on Monday-Wednesday and Wednesday-Friday with the significance below 5\%, on Monday-Thursday and TuesdayThursday with significantly below $10 \%$ for 10 winner LQ45. 10 loser LQ45 shows different result with having the result significant on Monday-Tuesday, Tuesday-Friday, and WednesdayFriday with the significance level below $10 \%$.

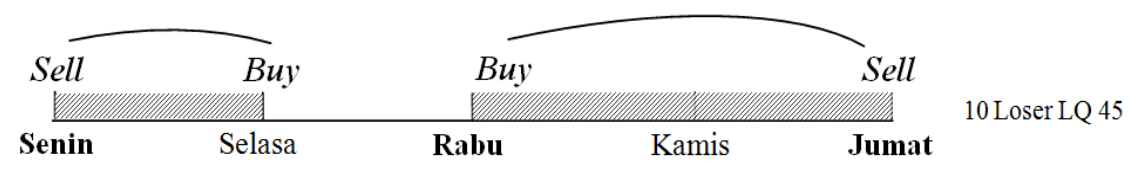

Figure 2. Summary Magnitude Drift Buy/Sell Decision on 10 Loser LQ45 
Magnitude drift effect on 10 winners LQ45 occurs on Monday-Wednesday, MondayThursday, Tuesday-Thursday, Wednesday-Friday, and Thursday-Friday. A significant positive magnitude drift occurs on Monday-Wednesday, Monday-Thursday and Tuesday-Thursday. The highest positive average of magnitude drift abnormal return occurs on Monday-Wednesday. A positive magnitude drift can be used for short selling decision. Investors can short sell by selling on Monday and buying on Wednesday. A negative significant magnitude drift occurs on Wednesday-Friday and Thursday-Friday. Thus investors can make decisions to buy on Wednesday and sell on Friday.

Ten loser LQ45 has different case where magnitude drift occurs on Monday-Tuesday, Tuesday-Friday, and Wednesday-Friday. A significant positive magnitude drift occurs on Monday-Tuesday. A positive magnitude drift can be used for short selling decision. Investors can short sell by selling on Monday and buying on Tuesday. A negative significant magnitude drift occurs on Tuesday-Friday and Wednesday-Friday. Thus, investors can make decisions to buy on Wednesday and sell on Friday.

Magnitude drift effect tends to occur on winner rather than loser. This is presumably due to the differences in the average spread of minimum share price spread and maximum share price, as well as the difference in the volume of transactions that trigger the overall dominant movement of stock prices for winner and loser. The difference of average minimum and maximum price spread of winner tends to be larger than loser's, which is why winner has bigger possibility of drift. On the other hand, the price movement of loser is triggered only by one share, while the movement of winner is triggered by a lot of shares. Thus, loser's stock movement is smaller compared to winner and magnitude drift occurs more frequently on winner.

\subsection{Days of the Week Effect FTSE100 Malaysia}

Table 7. Descriptive Statistic Results for Days of the Week Effect in 5 Winner FTSE100 Malaysia

\begin{tabular}{cccccc}
\hline Day & $\mathrm{N}$ & Mean & Std. Deviation & Minimum & Maximum \\
\hline Monday & 25 & 0.0117 & 0.0251 & -0.0182 & 0.1073 \\
Tuesday & 20 & 0.0088 & 0.0324 & -0.0442 & 0.0861 \\
Wednesday & 20 & 0.0058 & 0.0288 & -0.0513 & 0.0676 \\
Thursday & 20 & -0.0070 & 0.0437 & -0.0983 & 0.0965 \\
Friday & 20 & -0.0030 & 0.0337 & -0.1127 & 0.0392 \\
\hline Total & 105 & 0.0037 & 0.0331 & -0.1127 & 0.1073 \\
\hline
\end{tabular}

Descriptive statistic result for days of the week effect on the 5 winner FTSE100 Malaysia shows that the highest average abnormal return is on Monday at 0.0117 with the minimum value of -0.0182 and maximum value of 0.1073 ; while the lowest average abnormal return is on Thursday with a value that is equal to -0.0070 with the range of -0.0983 as the minimum value to 0.0965 as the maximum value. 
Table 8. Descriptive Statistic Results for Days of the Week Effect in 5 Loser FTSE100 Malaysia

\begin{tabular}{cccccc}
\hline Day & $\mathrm{N}$ & Mean & Std. Deviation & Minimum & Maximum \\
\hline Monday & 25 & 0.0074 & 0.0133 & -0.0276 & 0.0286 \\
Tuesday & 20 & 0.0024 & 0.0175 & -0.0358 & 0.0318 \\
Wednesday & 20 & 0.0038 & 0.0157 & -0.0402 & 0.0287 \\
Thursday & 20 & -0.0027 & 0.0135 & -0.0416 & 0.0218 \\
Friday & 20 & 0.0063 & 0.0189 & -0.0303 & 0.0524 \\
\hline Total & 105 & 0.0036 & 0.0159 & -0.0416 & 0.0524 \\
\hline
\end{tabular}

Descriptive statistic result for days of the week effect on the 5 loser FTSE100 Malaysia shows that the highest average abnormal return is on Monday at 0.0074 with the minimum value of -0.0276 and maximum value of 0.0286 ; while the lowest average abnormal return is on Thursday with a value that is equal to -0.0027 with the range of -0.0416 as the minimum value to 0.0218 as the maximum value.

Table 9. Summary of Daily Abnormal Return Test Result with Kolmogorov-Smirnov Normality Test, Run Test, and One Sample T-Test on 5 Winner FTSE100 Malaysia and 5 Loser FTSE100 Malaysia

\begin{tabular}{ccccccc}
\hline & \multicolumn{3}{c}{ 5 Winner FTSE100 Malaysia } & \multicolumn{3}{c}{ 5 Loser FTSE100 Malaysia } \\
\cline { 2 - 7 } Test & K-S & $\begin{array}{c}\text { Run } \\
\text { Test }\end{array}$ & $\begin{array}{c}\text { One } \\
\text { Sample T- } \\
\text { test }\end{array}$ & K-S & Run Test & $\begin{array}{c}\text { One Sample } \\
\text { T-test }\end{array}$ \\
\hline Monday & 0.307 & 0.650 & $0.029^{* *}$ & 0.604 & 0.831 & 0.100 \\
Tuesday & 0.355 & 0.598 & 0.240 & 0.987 & 1.000 & 0.556 \\
Wednesday & 0.991 & 0.818 & 0.376 & 0.732 & 0.491 & 0.291 \\
Thursday & 0.542 & 0.223 & 0.483 & 0.385 & 0.962 & 0.385 \\
Friday & 0.390 & 0.761 & 0.694 & 0.181 & 0.109 & 0.155 \\
\hline
\end{tabular}

Notes: symbol ** illustrates the significance level below $5 \%$.

Normality test is done by Kolmogorov-Smirnov at the significance level of 5\% indicates that the test is conducted from Monday to Friday for 5 winners of FTSE100 Malaysia and 5 losers of FTSE100 Malaysia are above 0.05, means the data is normal and further testing can be done. Run Test conducted with significance level at 5\% and the results are above 0.05 on Monday, Tuesday, Wednesday, Thursday, and Friday for 5 winner FTSE100 Malaysia and 5 loser FTSE100 Malaysia; means the data has been distributed randomly and further testing can be done.

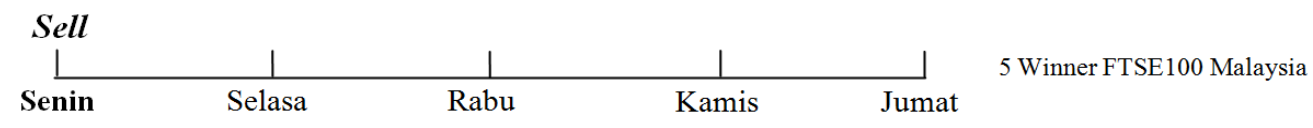

Figure 3. Summary Buy/Sell Decision on 5 Winner FTSE100 Malaysia

Test for days of the week effect on 5 winners FTSE100 Malaysia indicates a significant difference of abnormal return on Monday with the average of 0.0117 that happens to be the highest average compared to other days. Thus, investors may decide to sell on Monday. While for 5 loser FTSE100, there is no significant result on any day which means there is days of the week phenomenon. 
Previous studies have consistently indicated that abnormal return is contrary at the lowest point on Monday. This may because of the self-fulfilling prophecy that caused investors to realize the prophecy itself; so that investors believe the results of previous studies by make a buy decision on Monday. The high amount of stocks bought on Monday led to a high demand, thus stock price increased. This research finds that the average abnormal return on Monday is significantly positive compared to other days.

Based on the test results of independent sample t-test result, Monday is significantly different from Thursday. This is because the average abnormal return on Thursday is likely to be the most negative compared to other days but not significant. The standard deviation of Thursday is the greatest among all. Thus, investors should sell on Monday as it is significantly differ from zero and have an average abnormal return higher than other days.

This is different from the days of the week effect test on 5 losers FTSE100 whereas there are no significant differences between days thus there is no days of the week effect on 5 loser FTSE100. It is suspected because of the difference between the average spread of share price during the highest and the lowest, as well as differences in the transaction volume of the winner and loser. The average spread on the winner's share price is greater than the loser FTSE100. This causes the average spread of share price on loser FTSE100 smaller than winner FTSE100, thus the possibility to earn abnormal return is smaller due to the price fluctuations that are not so enormous for loser FTSE100 compared to winner FTSE100. The sheer opportunities to earn abnormal return causes the absence of days of the week effect phenomenon on 5 loser FTSE100. This is also supported by the winner's total volume of transactions that is 5 times greater than loser's, thus the movement of stock prices tends to be active and have a high transaction volume.

\subsection{Magnitude Drift Effect FTSE100 Malaysia}

\section{Table 10. Descriptive Statistics Result for Magnitude Drift Effect in 5 Winner FTSE100}

\begin{tabular}{cccccc} 
Shift Day $(\Delta \mathrm{AR})$ & $\mathrm{N}$ & Mean & Std. Deviation & Minimum & Maximum \\
\hline Monday-Tuesday & 20 & 0.0071 & 0.0445 & -0.0794 & 0.1515 \\
Monday-Wednesday & 20 & 0.0154 & 0.0353 & -0.0555 & 0.0861 \\
Monday-Thursday & 20 & 0.0187 & 0.0524 & -0.1017 & 0.1133 \\
Monday-Friday & 20 & 0.0147 & 0.0463 & -0.0466 & 0.1486 \\
Tuesday-Wednesday & 20 & -0.0060 & 0.0257 & -0.0700 & 0.0387 \\
Tuesday-Thursday & 20 & 0.0116 & 0.0569 & -0.0855 & 0.1801 \\
Tuesday-Friday & 20 & 0.0076 & 0.0345 & -0.0372 & 0.1188 \\
Wednesday-Thursday & 20 & 0.0128 & 0.0579 & -0.0631 & 0.1659 \\
Wednesday-Friday & 20 & 0.0088 & 0.0475 & -0.0652 & 0.1605 \\
Thursday-Friday & 20 & -0.0040 & 0.0492 & -0.1342 & 0.0933 \\
\hline Total & 200 & 0.0063 & 0.0460 & -0.1342 & 0.1801 \\
\hline
\end{tabular}

Descriptive statistics result for magnitude of the drift effect in 5 winner FTSE100 shows that the biggest positive average change on abnormal return occurs on Monday-Thursday with the value of 0.0187 with the range of -0.1017 as minimum value, and 0.1133 as maximum value; and the biggest negative average change on abnormal return occurs on TuesdayWednesday with the value of -0.0060 . The average of abnormal return change tends to be positive on Monday-Tuesday, Monday-Wednesday, Monday-Thursday, Monday-Friday, Tuesday-Thursday, Tuesday-Friday, Wednesday-Thursday, and Wednesday-Friday; while the 
average of abnormal return changes tends to be negative on Tuesday-Wednesday and Thursday-Friday. The biggest standard deviation occurs on Wednesday-Thursday with average changes in abnormal returns of 0.0579 , means Wednesday-Thursday has the biggest volatility on abnormal return change compared to other days with minimum value of -0.0631 , up to maximum value of 0.1659 .

Table 11. Descriptive Statistic Result of Magnitude Drift Effect on 5 Losers FTSE100

\begin{tabular}{cccccc} 
Shift Day $(\Delta \mathrm{AR})$ & $\mathrm{N}$ & Mean & Std. Deviation & Minimum & Maximum \\
\hline Monday-Tuesday & 20 & 0.0054 & 0.0197 & -0.0314 & 0.0324 \\
Monday-Wednesday & 20 & 0.0039 & 0.0215 & -0.0389 & 0.0436 \\
Monday-Thursday & 20 & 0.0104 & 0.0183 & -0.0251 & 0.0484 \\
Monday-Friday & 20 & 0.0015 & 0.0201 & -0.0458 & 0.0392 \\
Tuesday-Wednesday & 20 & -0.0051 & 0.0262 & -0.0425 & 0.0670 \\
Tuesday-Thursday & 20 & 0.0050 & 0.0252 & -0.0315 & 0.0683 \\
Tuesday-Friday & 20 & -0.0039 & 0.0253 & -0.0715 & 0.0387 \\
Wednesday-Thursday & 20 & 0.0065 & 0.0143 & -0.0167 & 0.0293 \\
Wednesday-Friday & 20 & -0.0025 & 0.0237 & -0.0445 & 0.0344 \\
Thursday-Friday & 20 & -0.0090 & 0.0197 & -0.0439 & 0.0140 \\
\hline Total & 200 & 0.0009 & 0.0220 & -0.0715 & 0.0683 \\
\hline
\end{tabular}

Descriptive statistics result for magnitude of the drift effect in 5 loser FTSE100 shows that the biggest positive average change on abnormal return occurs on Monday-Thursday with the value of 0.0104 and Wednesday-Friday with the value of -0.0025 . The average of abnormal return change tends to be positive on Monday-Tuesday, Monday-Wednesday, MondayThursday, Monday-Friday, Tuesday-Friday, and Wednesday-Friday; while the average of abnormal return changes tends to be negative on Tuesday-Wednesday, Tuesday-Friday, Wednesday-Friday, and Thursday-Friday. The biggest standard deviation occurs on TuesdayFriday with average changes in abnormal returns of 0.025 , means Tuesday-Friday has the biggest volatility on abnormal return change compared to other days.

Normality test is done by Kolmogorov-Smirnov at the significance level of 5\% indicates that magnitude drift effect test conducted on Monday-Tuesday, Monday-Wednesday, MondayThursday, Monday-Friday, Tuesday-Wednesday, Tuesday-Thursday, Tuesday-Friday, Wednesday-Thursday, Wednesday-Friday, and Thursday-Friday for 5 winners of FTSE100 and 5 losers of FTSE100 are above 0.05, means the data is normal and further testing can be done. Run Test is conducted with the significance level at 5\% and the results are above 0.05 on Monday-Tuesday, Monday-Wednesday, Monday-Thursday, Monday-Friday, TuesdayWednesday, Tuesday-Thursday, Tuesday-Friday, Wednesday-Thursday, Wednesday-Friday, and Thursday-Friday for 5 winner FTSE100 and on Monday-Tuesday, Monday-Wednesday, Monday-Thursday, Monday-Friday, Tuesday-Wednesday, Tuesday-Thursday, and WednesdayFriday for 5 loser FTSE100; means the data has been distributed randomly. Run Test for Tuesday-Friday and Thursday-Friday on 5 loser FTSE100 shows that it is under 0.05 , means the data is not distributed randomly. 
Table 12. Summary of Test Result with Magnitude Drift on Abnormal Return Daily using the Kolmogorov Smirnov Normality Test, Run Test, and One Sample T-Test on 5 Winner FTSE100 and 5 Loser FTSE100

\begin{tabular}{ccccccc}
\hline & \multicolumn{3}{c}{ 5 Winner FTSE100 } & \multicolumn{3}{c}{ 5 Loser FTSE100 } \\
\cline { 2 - 7 } Test & K-S & $\begin{array}{c}\text { Run } \\
\text { Test }\end{array}$ & $\begin{array}{c}\text { One } \\
\text { Sample } \\
\text { T-test }\end{array}$ & K-S & $\begin{array}{c}\text { Run } \\
\text { Test }\end{array}$ & $\begin{array}{c}\text { One } \\
\text { Sample } \\
\text { T-test }\end{array}$ \\
\hline Monday-Tuesday & 0.397 & 1.000 & 0.486 & 0.934 & 0.781 & 0.235 \\
Monday-Wednesday & 0.987 & 0.781 & $0.067^{*}$ & 0.678 & 0.839 & 0.425 \\
Monday-Thursday & 0.920 & 0.108 & 0.127 & 0.737 & 0.227 & $0.020^{* *}$ \\
Monday-Friday & 0.375 & 0.839 & 0.171 & 0.656 & 0.314 & 0.747 \\
Tuesday-Wednesday & 0.904 & 0.251 & 0.306 & 0.425 & 0.314 & 0.390 \\
Tuesday-Thursday & 0.701 & 0.853 & 0.372 & 0.844 & 1.000 & 0.382 \\
Tuesday-Friday & 0.323 & 0.853 & 0.334 & 0.631 & 0.041 & 0.497 \\
Wednesday-Thursday & 0.983 & 0.251 & 0.334 & 0.936 & 1.000 & $0.057^{*}$ \\
Wednesday-Friday & 0.531 & 0.962 & 0.415 & 0.725 & 0.265 & 0.648 \\
Thursday-Friday & 0.962 & 0.781 & 0.721 & 0.056 & 0.007 & $0.056^{*}$ \\
\hline
\end{tabular}

Notes: symbol * illustrates the significance level below $10 \%$, symbol ** illustrates the significance level below $5 \%$, symbol $* * *$ illustrates the significance level below $1 \%$.

One sample t-test is used for hypotheses test differ from zero. The result shows that it is significant on Monday-Wednesday with the significance level below $10 \%$ for 5 winner FTSE100. 5 loser FTSE100 shows different result with having the result significant on Wednesday-Thursday and Thursday-Friday with the significance level below $10 \%$, as well as on Monday-Thursday with the significance level below $5 \%$.

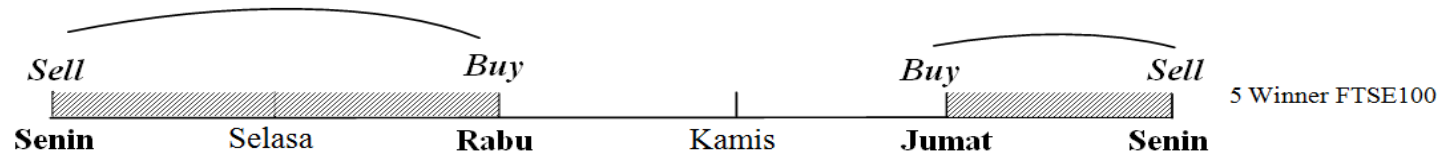

Figure 4. Summary Magnitude Drift Buy/Sell Decision on 5 Winner FTSE100

Magnitude drift effect on 5 winner FTSE100 occurs on Monday-Wednesday with a positive drift. Investors can short sell by selling on Monday and buying on Wednesday. This research also adds Friday-Monday to study the magnitude drift of 5 winner FTSE100. A significant negative magnitude drift occurs on FridayMonday with the average magnitude drift abnormal return of -0.017 . Thus, investors can make a buy decision on Friday and sell on Monday to earn the biggest magnitude drift abnormal return on 5 winner FTSE100.

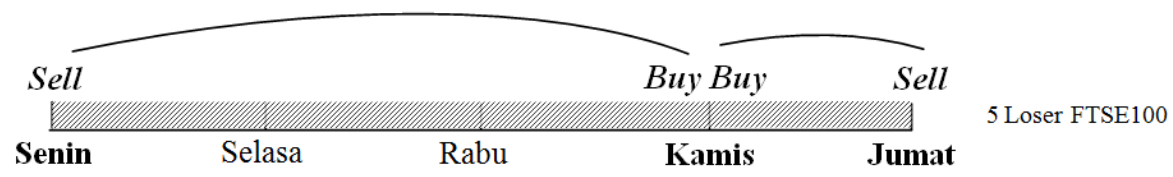

Figure 5. Summary Magnitude Drift Buy/Sell Decision in 5 loser FTSE100

In table 5.10, 5 loser FTSE100 has different case where magnitude drift occurs on MondayThursday, Wednesday-Friday, and Thursday-Friday. A significant positive magnitude drift occurs on Monday-Thursday and Wednesday-Thursday with Monday-Thursday as the most positive one. A positive magnitude drift can be used for short selling decision. Investors can 
short sell by selling on Monday and buying on Thursday. A negative significant magnitude drift occurs on Thursday-Friday with the average magnitude drift abnormal return -0.008 . Thus investors can make decisions to buy on Thursday and sell on Friday.

Magnitude drift effect tends to occur on loser FTSE100 rather than on winner FTSE100. This is presumably due to differences in the average stock price multiplied by the listed shares held by the winner and loser FTSE100. The higher that point owned by loser FTSE100 then the transaction volume will be greater, thus there will be a larger movement and it will lead to drift. Therefore, the magnitude of drift occurs more frequently in the loser FTSE100 than the winner.

\subsection{Comparison Result of LQ45 and FTSE100}

Overall, the days of the week effect have the same result, with the significant difference of abnormal return average on Monday as the highest and occur only in winner. Magnitude drift that occurs in LQ 45 group tends to be greater than the one that occurs FTSE100 Malaysia. This is presumably caused by the differences on market capitalization between LQ45 and FTSE100 Malaysia, and differences of risk premium in Indonesia and Malaysia. The market capitalization of the 10 winner and 10 loser LQ45 is greater than the market capitalization of 5 winner and 5 loser FTSE100 Malaysia. This proves that the market capitalization would affect the magnitude drift that occurs in both countries. The greater the number of shares and price per share will cause a greater power on capital market and form magnitude drift effects.

In addition to this, risk premium also affect investors' preference to invest in Indonesia or Malaysia. A high-risk premium indicates large fluctuations and may affect the required return. Risk premium in Indonesia is greater than Malaysia, thus the required return in Indonesia is higher and more attractive for investors.

\section{Conclusion}

There are days of the week effect phenomenon on Mondays and Fridays in 10 winner LQ45 with the highest significant differences in the average of abnormal return on Monday and the lowest significant difference of average abnormal return on Friday, while there are no days of the week effect phenomenon on 10 loser LQ45. There are days of the week effect phenomenon on Monday in 5 winner and 5 loser FTSE100 with a highest significant difference in the average of abnormal return on Monday. There is magnitude drift effect phenomenon on 10 winner LQ45 and 10 loser LQ45. On 10 winner LQ45, there are positive magnitude drift on Monday-Tuesday, Tuesday-Friday, and Wednesday-Friday and negative magnitude drift on Wednesday-Friday and Thursday-Friday. On 10 loser LQ45, there are significant positive magnitude drift on Monday-Wednesday, Monday-Thursday and Tuesday-Thursday, while the significant negative magnitude drift occurs on Wednesday-Friday and Thursday-Friday. There is magnitude drift effect phenomenon on 5 winner FTSE100 and 5 loser FTSE100. On 5 winner FTSE100, there is positive magnitude drift on Monday-Wednesday and negative magnitude drift on Friday-Monday. On 5 loser FTSE100, there are significant positive magnitude drift on Monday-Thursday, Wednesday-Friday, and Thursday-Friday, while the significant negative magnitude drift occurs on Thursday-Friday. LQ45 has more magnitude drift compared to FTSE100 Malaysia.

The limitation on this research is the determination of the winner and loser only on short term, thus there might be a bias in the decision making, the short sell recommendation is also limited for particular investors and not all investors can do the same, and the research object is limited. It is expected that further research add another research object from different countries with a longer period. 


\section{References}

Aggarwal R, Rivoli P. 1989. Seasonal and Day of the Week Effects in Four Emerging Stock Markets. The Financial Review. 24(7): 541-550.

Alteza M. 2007. Efek Hari Perdagangan Terhadap Return Saham: Suatu Telaah atas Anomali Pasar Efisien. Thesis. Universitas Negeri Yogyakarta.

Berk G. 2009. Stock Returns and The Day of the Week Effect in Istanbul Stock Exchange. Journal of Applied Economics. 35(8): 959-971.

Cross F. 1973. The Behavior of Stock Prices on Fridays and Mondays. Financial Analysts Journal. 29: 67-69.

Damodaran A. 1996. Investment Valuation: Tools and Techniques for Determining the Value of Any Asset. New York: Wiley.

Fama E. 1970. Efficient Capital Markets - A Review of Theory and Empirical Work. Journal of Finance. 25: 383-417.

French KR. 1980. Stock Returns and the Weekend Effect. Journal of Financial Economics. 8(1): 55-69.

Jones CP. 1998 Investment Analysis and Management 9th edition. Chichester UK: John Wiley \& Sons.

Keim DB, Stambaugh F. 1984. A Further Investigation of Weekend Effects in Stock Returns. Journal of Finance. 39(3): 819-835.

Lari MK, Mardani A, Aghaeiboorkheili M. 2013. Day of The Week Effect, Annual Returns and Volatility of Five Stock Markets in Southeast of Asia. Asian Journal of Finance \& Accounting. 5(1): 446-461.

Megginson WL. 2007. Corporate Finance Theory. Massachusetts: Addison-Wesley. 